Vol.16, No. 58, January, 2021, 175--184

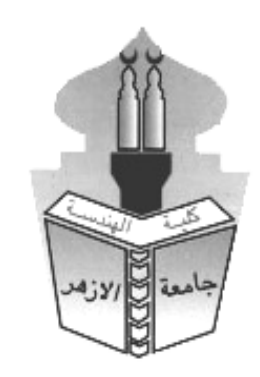

\title{
FRACTAL GEOMETRY AS A FUNCTIONAL AND FORMATIVE METHOD IN THE INTERIOR ARCHITECTURE
}

\author{
Zainab Mohamed Abdel Moez* and Tariq Kamal El Din Adly \\ Decoration Department, Interior Architecture Division, Faculty of Fine Arts, Minia \\ University, Minia, Egypt. \\ *Corresponding Author E-mail: Zeinab Mohamed @ yahoo.com
}

\begin{abstract}
:
Fractal geometry can be applied in interior architecture by using certain shapes that depend on the principle of self-similarity and repeating the shape to an infinite number of times, and one of the most popular shapes that can be applied is the Cantor group that can be used as a basis in completing the facades and the locations of doors and windows. For snowflakes, which can be used in devising various forms of decoration, also the Serpinsky Triangle, which is considered one of the most important forms of fractal geometry, which can be applied in internal architecture. It is formed by following the molecular fractals of the components of a small molecule. Use it to generate multiple ideas to make shapes for horizontal projections, whether internal or external.
\end{abstract}

\section{KEYWORDS : Fractal Geometry, Cantor Set, Cottage Curve, Sirbinskii Triangle, Geometric Iterations.}

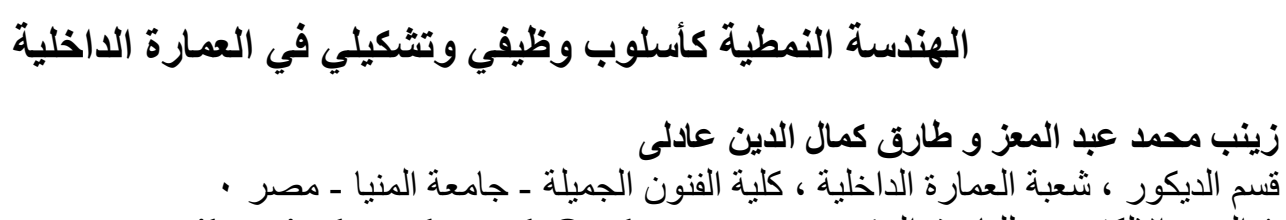

E- mail: Zeinab Mohamed @yahoo.com : البريد الالكتروني للباحث الرئيسية،

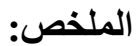

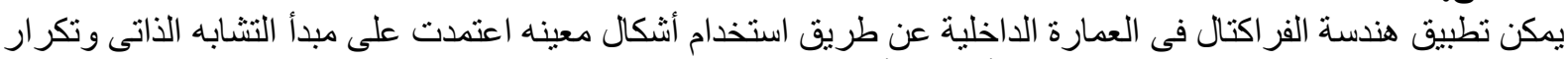

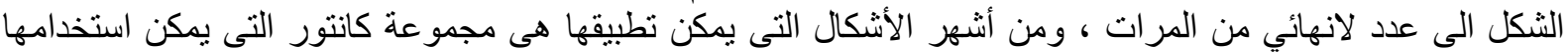

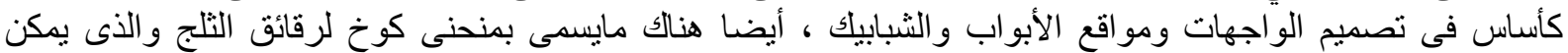

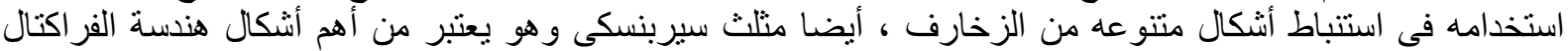

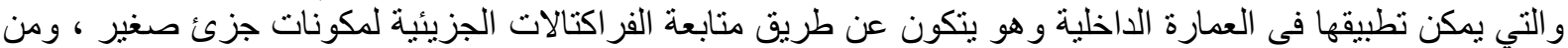

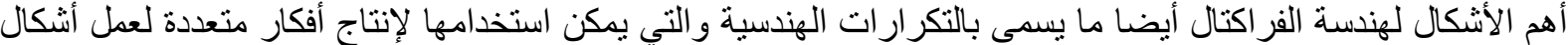

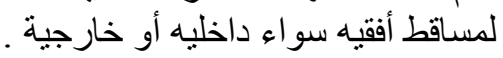

الكلمات المفتاحيه : الهندسة النمطية، مجموعة كانتور، منحنى كوخ، مثلث سيربنسكى، التكرارات الهندية .

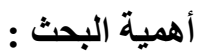

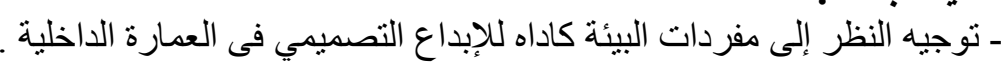

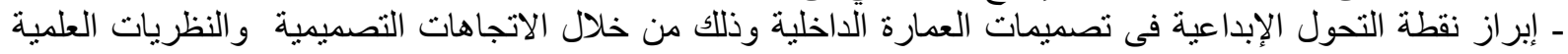
الحديثة و التى تعتمد على مفهوم محاكاة الطبيعة في العملية التصميمية ونظرية الهندة التهة النمطية.
} 
ـ ـ دراسة مفهوم نظرية الهندسة النمطية و أثر ها على العمارة الداخلية . ــ إلقاء الضوء على علاقلة النظريات الرياضية بالطبيعة وتأثنير ها على تصميمات العمارة الداخلية .

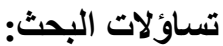
كيفية تطبيق الهندسة النمطيه في العمارة الاخلية ؟

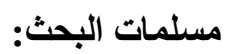
ـ الهندسة النمطية نظريه علمية رياضيه لوصف الطبيعة.

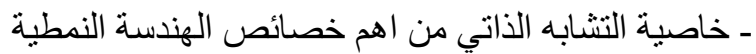

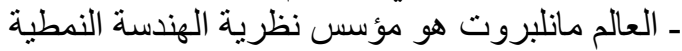

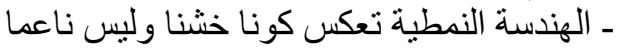
ـ الهندسة النمطية من النظريات العلمية التى يعتقد أنها استجابة ما بعد الحداثة

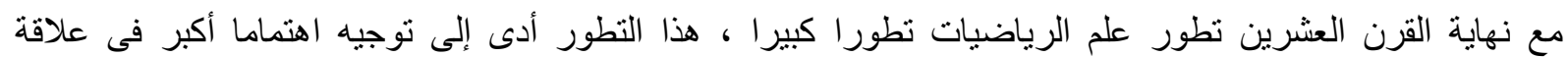

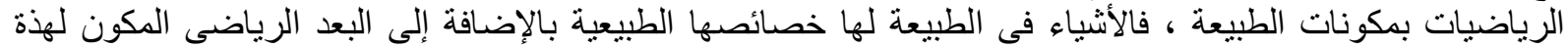

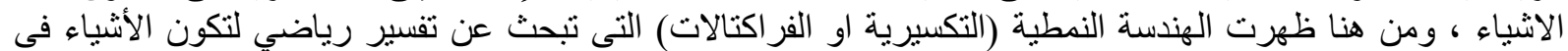

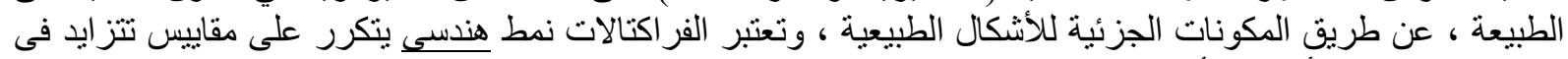

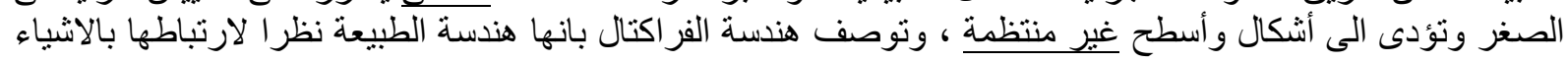

تبعد هندسة الفر اكتال أو ما يسمى بالهندسة النمطية نموذج للرياضيات العصرية التي ظهرت نتيجة نتئة نظريات حديثة ، الطبيعية .

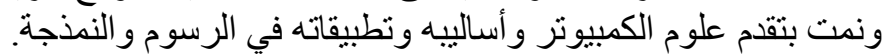

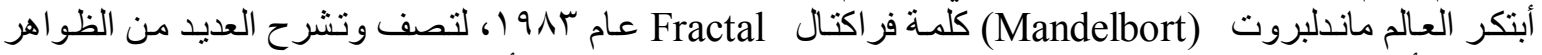

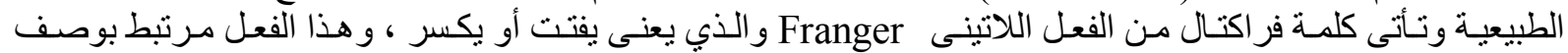

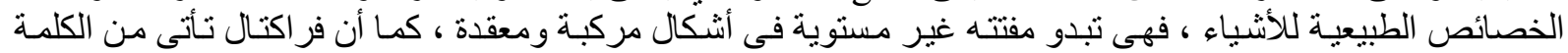

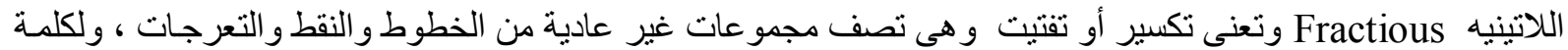

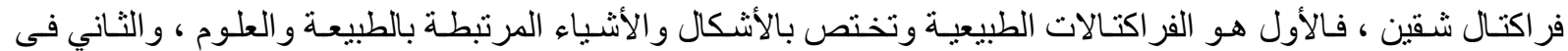

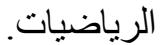

\section{r - ارتباط الهندسة النمطية بالطبيعة} وتسمى أيضا بهندسة الطبيعة حئيثة بالطبعة تصف الجبال و السحب و الأشجار .... و غير هم بالإضافة لكونها نمونجاً يحتضن الفن

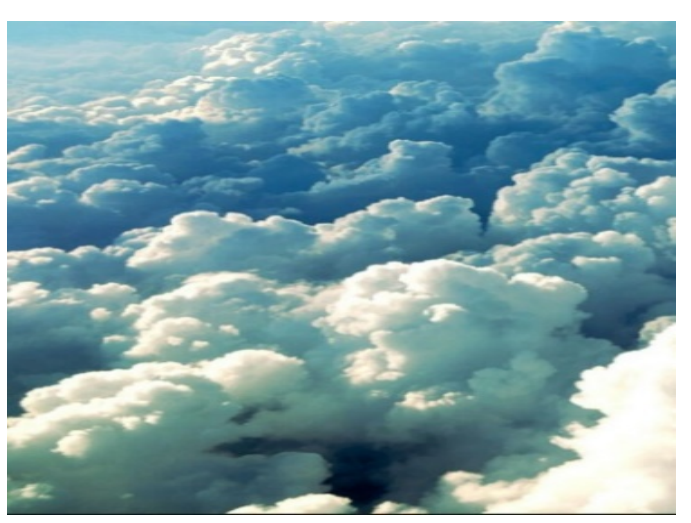
الرياضي القديم و الحديث.

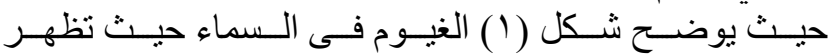

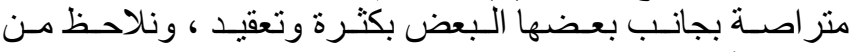

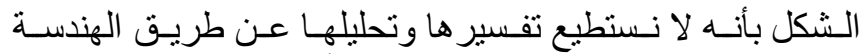

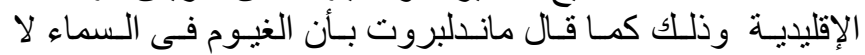

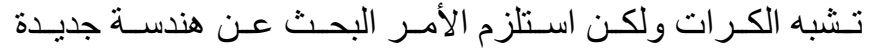

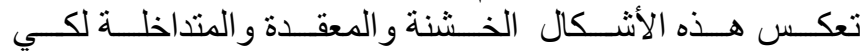
نستطيع فهم الطبيعة وتحليل الأشكال المتداخلة والمعقدة بها.

شكل (1) يوضح الغيوم المتكررة والمعقدة في تركيبها والتى يمكن تفسير ها بالهندسة النماندية تركية 


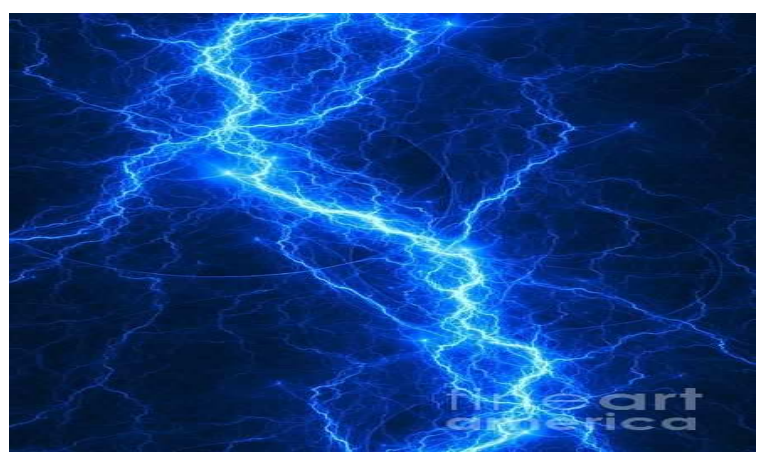

ويتضح فى شكل (r) خطوط البرق المتنـاثرة

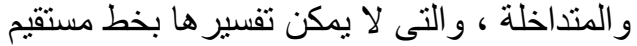

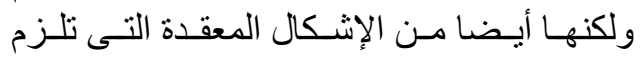

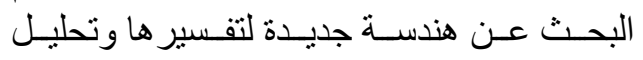

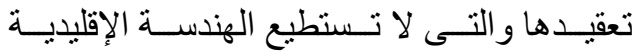

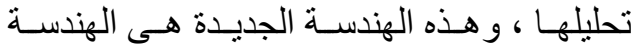

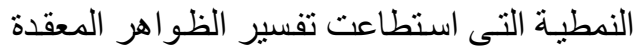
الكامنة فى الطبيعة وتحليلها.

شكل (ץ) يوضح خطوط البرق المتعرجة المكررة والتى تأخذ أشكالا متعددة ومتذاخله r ـ تطبيق هندسة الفراكتال في العماره الداخليه:

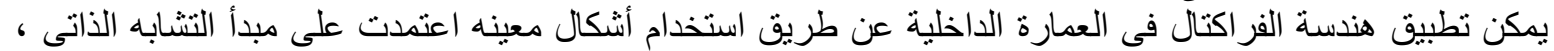

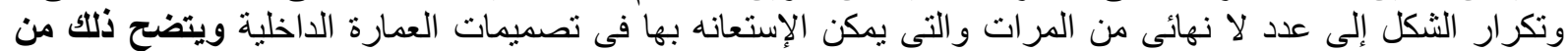

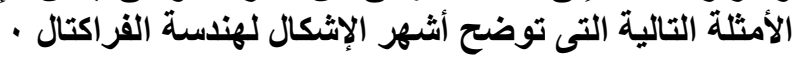

أولا:مجموعة كانتور Cantor Set:.

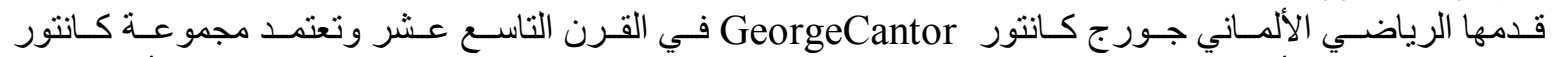

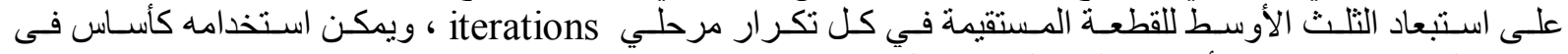
تصميم الو اجهات ومو اقع الأبواب و الثبابيك بها شكل (r) ، ( (ع).

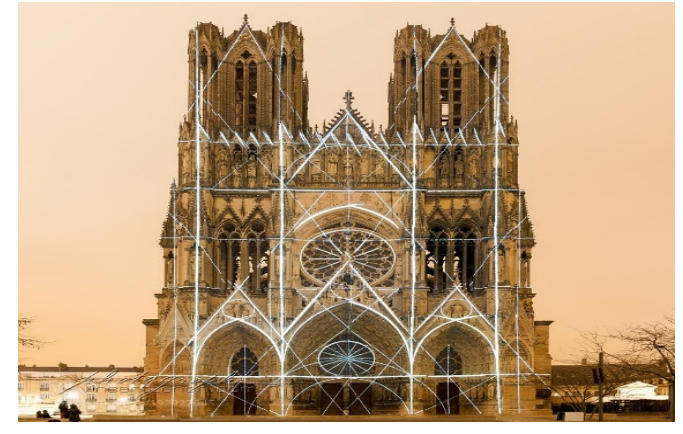

شكل ( ) يوضح نموذج لأحد واجهات الكاتدرائيات

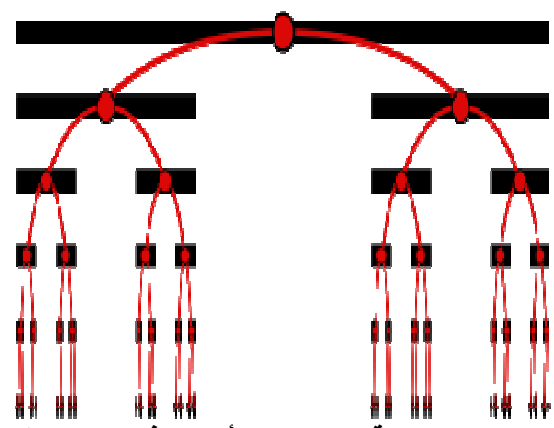

شكل(") يوضح إمكانية استخدامه كأساس فى تصميم الواجهات

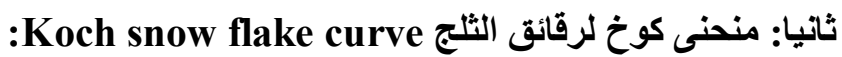

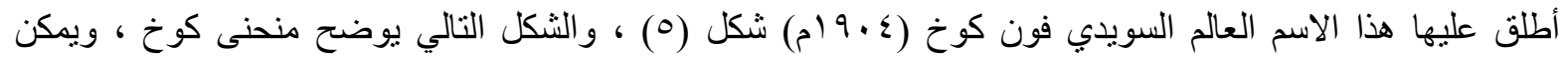

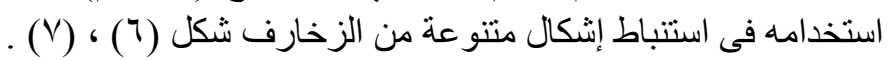

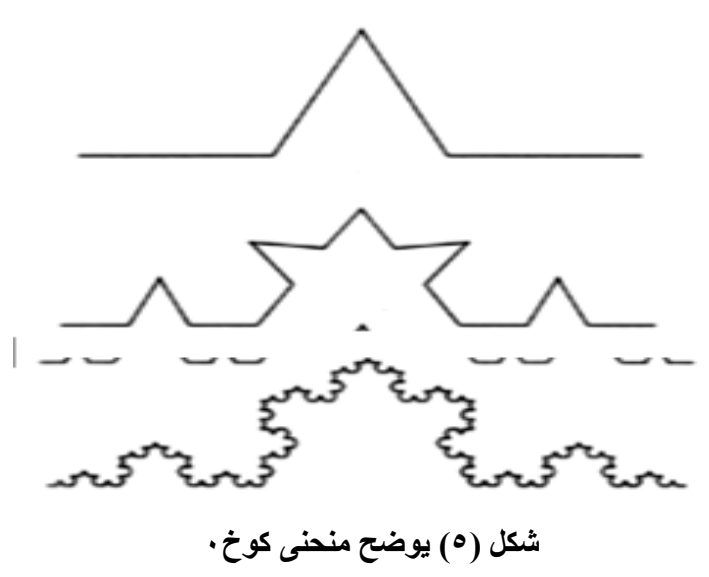




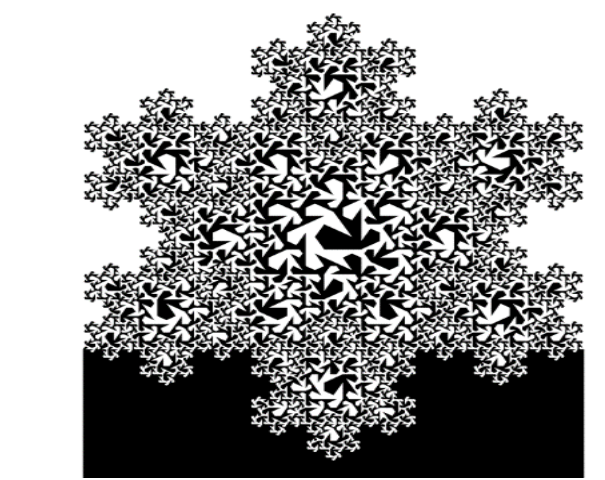

شكل (V) يوضح زخرفه أخرى يمكن استتباطها من التكرار

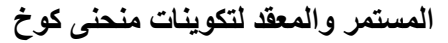

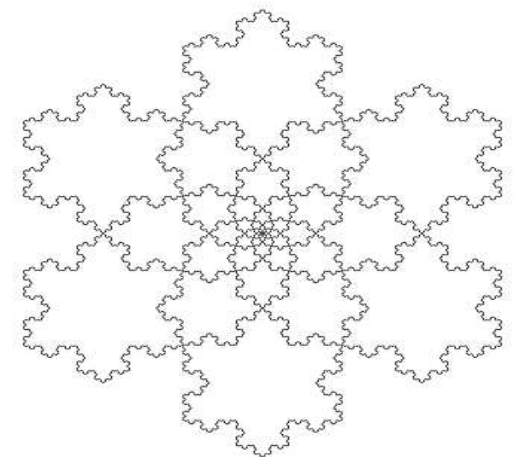

شكل (†) يوضح زخرفه يمكن استنباطها من التثابه الذاتى لتكوينات

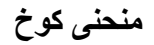

ثالثا: مثلث سيربنسكي:Sierpinsk

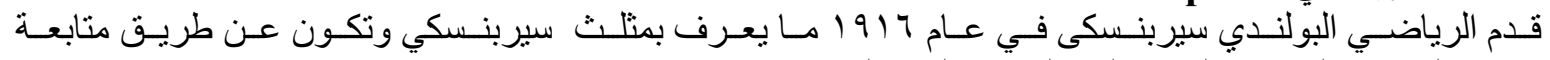
الفركتلات الجزيئية الموسعة التي شكلتها التجميع الذاتي لمكونات جزيء صغير بـرفير

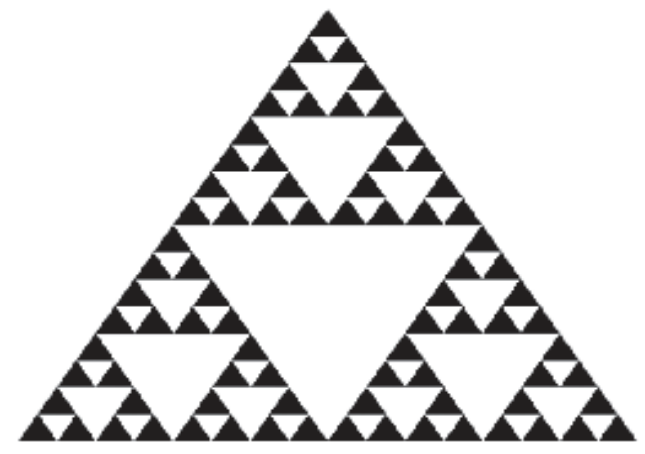

شكل (^) يوضح مثلث سيربنسكى و هو من أهم أشكال الهندسه النمطيه والذى

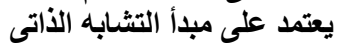

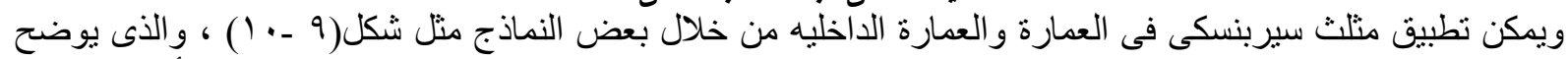

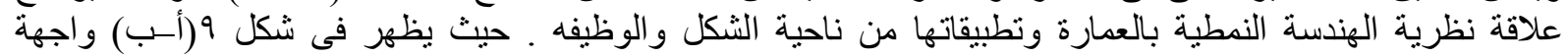

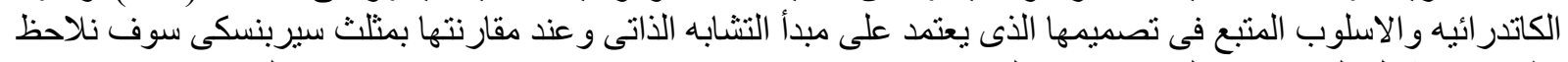

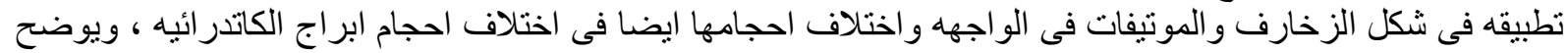

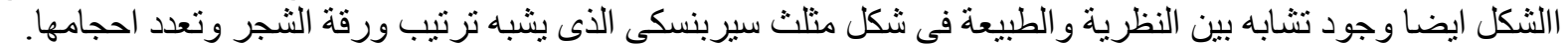

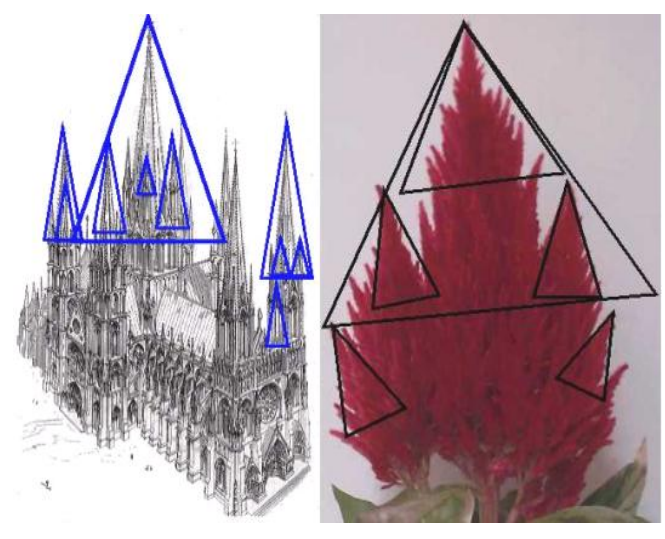

(ب)

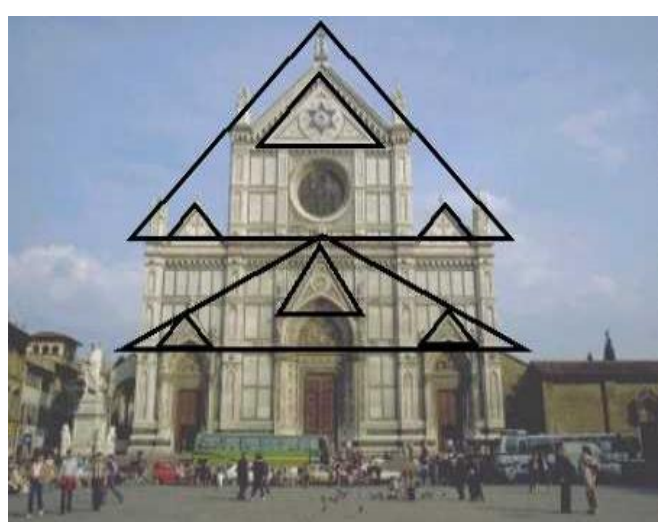

(

شكله ( أ - ب ) يوضح تطبيقات مثلث سيربنسكى فى شكل الكاتدرائيات والأى يثبه فى ترتيبه ورقة الثجر

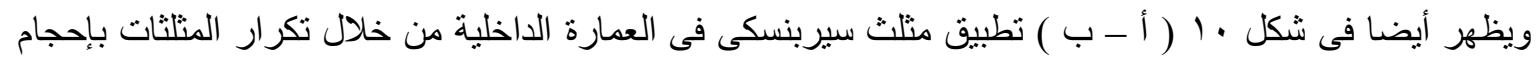

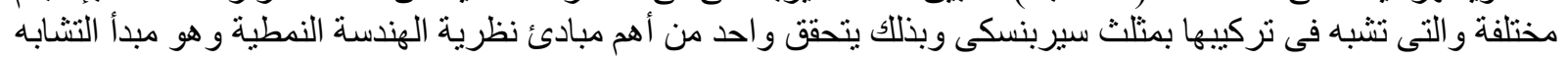


الذاتي فى التصميم وفى الثكل بظهر أيضا من الناحية الوظيفية استخدام هذه المثلثات كفتحات للإضاءة و التهوية أعطت شكلا إبداعيا للفر اغ وغير تقليدي.

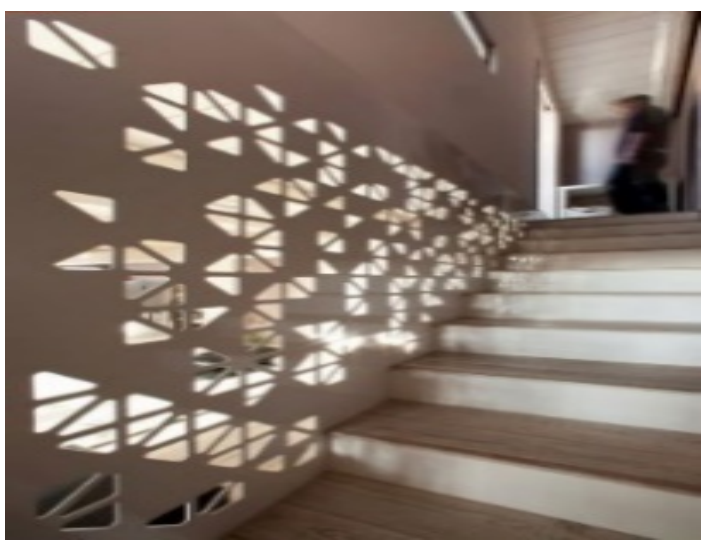

(ب)

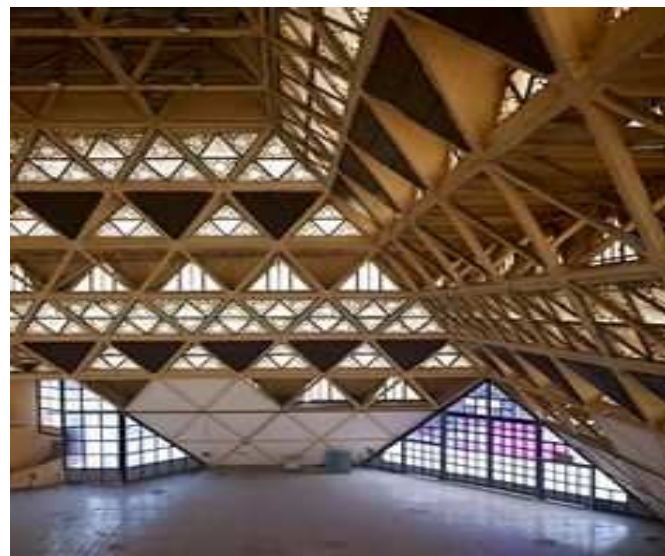

(

شكل · ( أ - ب ) يوضح تطبيقات مثلث سيرينسكى فى العمارة الداخليه من خلال تكرار المثلثات باحجام مختلفة

رابعا:التكرارات الهندسية :

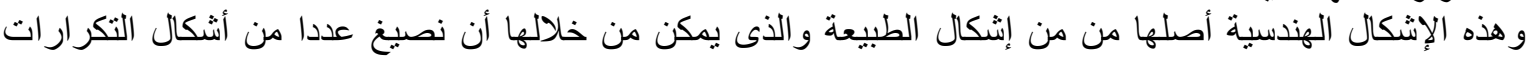

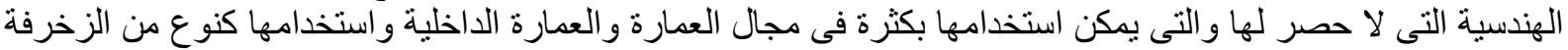

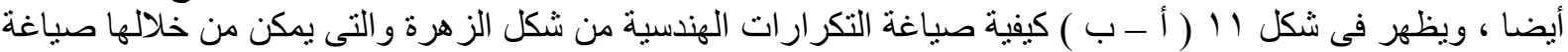

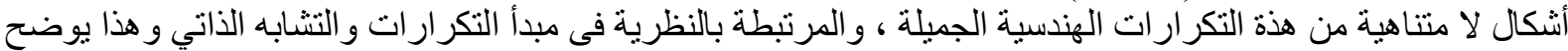
أكثر ارتباط النظرية بالطبيعة ارتباطا وثيقا ولذلك سميت بهندسة الطبيعة.

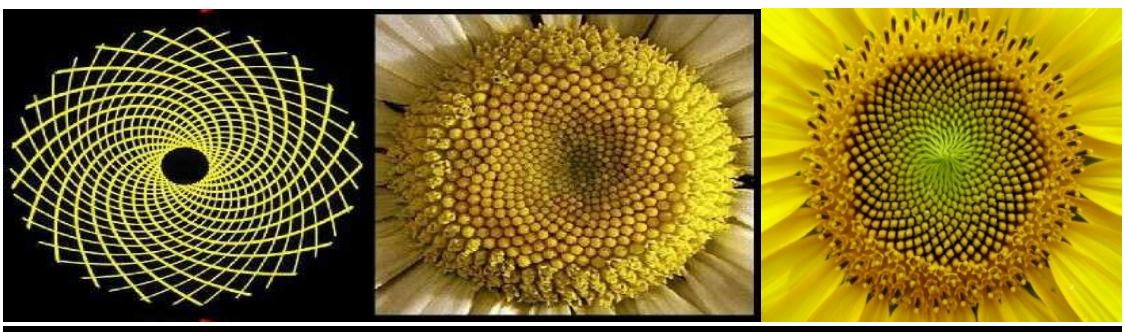

(
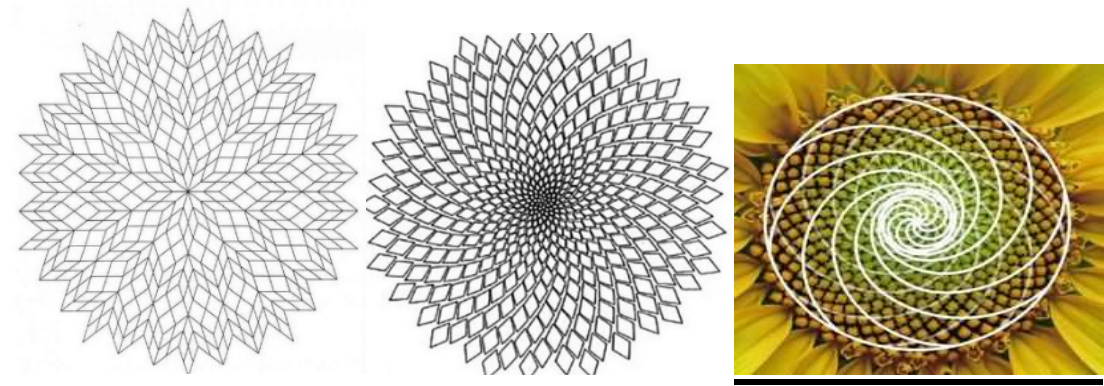

(ب)

شكل ل1 1 ( أ ـ ب ) توضح أيضا كيفية صياغة إثكال مختلفة ولا متناهية من شكل الزهرة

ويمكن استخدام فر اكتال التكرارات الهندسية فى العمارة من خلال استخدامها لإنتاج أفكار مختلفة متعددة لعمل إثكال

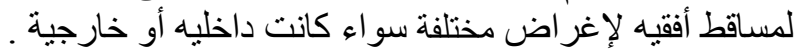

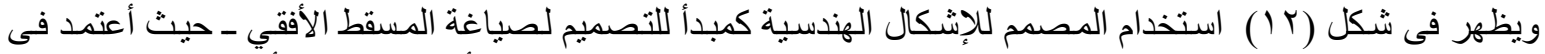

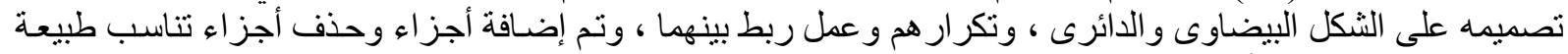
الاستخدام لتعطى مسقط أفقى يلبى احتياج المكان ويحقق الوظيفة والثكل المطلوبين ، ومن شكل المسقط نلاحظ انـه مخطط 
لفيلال سكنيه ، تم عمل غرفها على شكل بيضاوى ، ثم عمل أضسافه لدائرة خارجية كبيرة تربط جميع الفر اغات ببعضها البعض و الاستفادة منها فى عمل مطلات خارجية و أماكن تشجير تطل علئ عليها جميع غرف الفيلا.
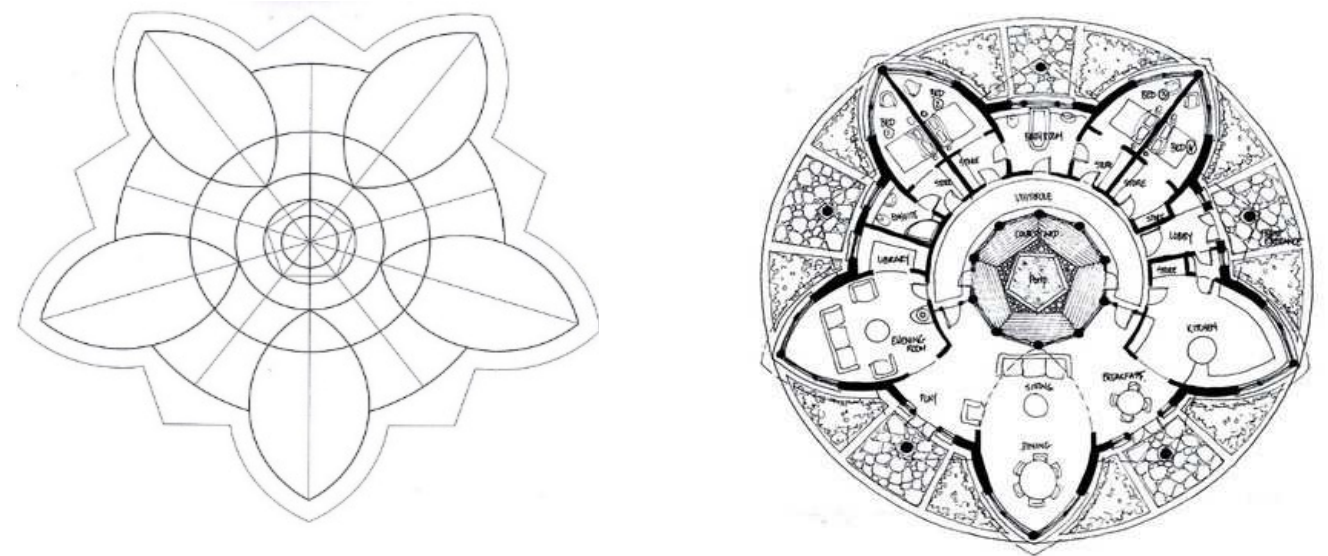

شكل (r ( ) يوضح استخدام مبدأ التكرارات الهندسية لإنشاء مسقط أفقي يخدم الوظيفه.

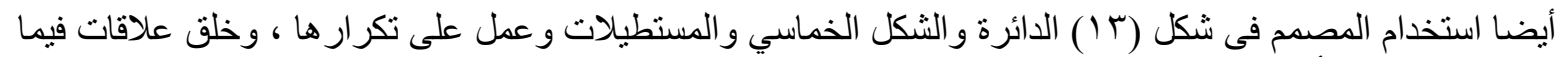

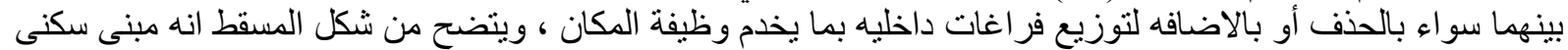

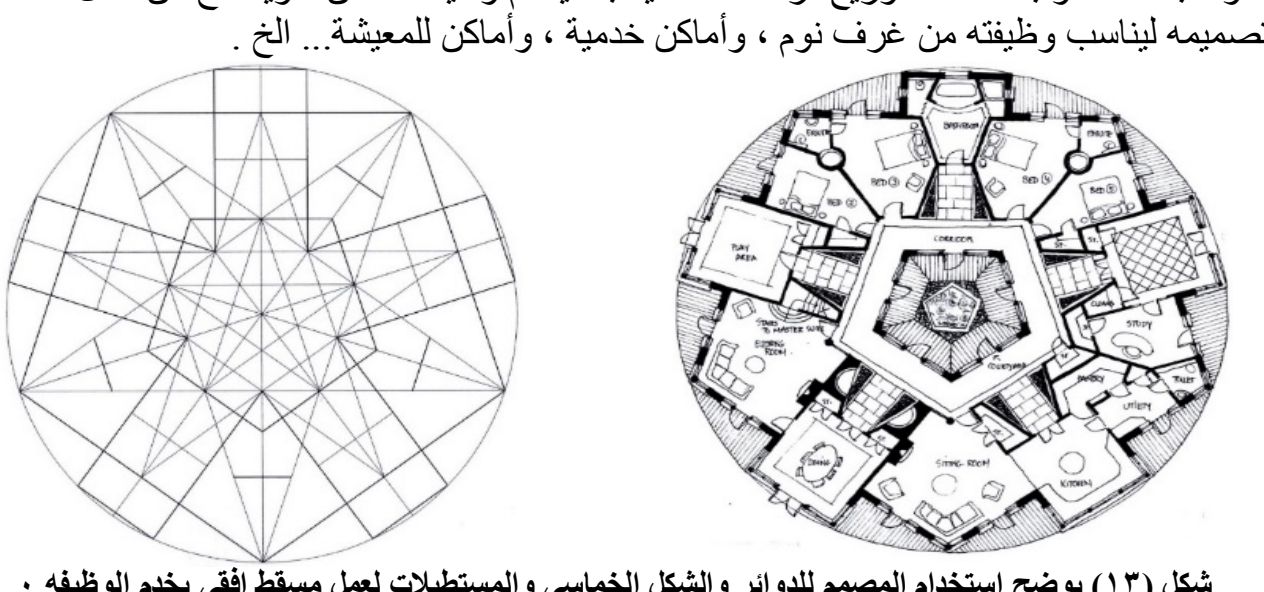

أما فى شكل (ع () استخدام المصمم أشكال هندسيه متعددة مثل الثكل الخماسي والسداسي والدوائر ، وتم توصيل

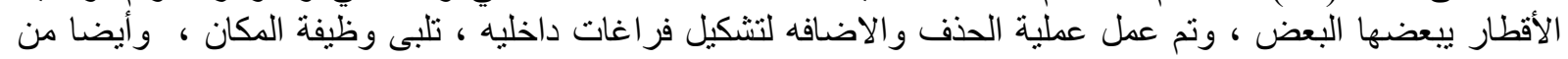

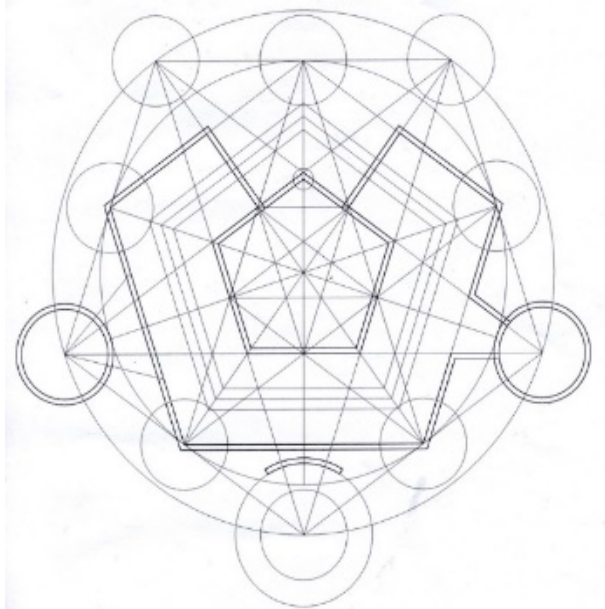
شكل المسقط يتضح انه مبنى سكنى.

شكل ( ؛ ( ) يوضح إستخدام المصمم للشكل الخماسى والسداسى والدوائر فى تقسيم الفراغات 
ع ـ تناول بعض العناصر الوظيفية فى العمارة الاخلية من خلال خصائص الهندسة النمطية :

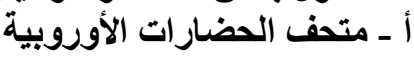

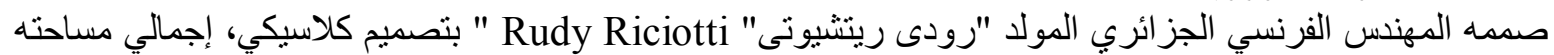

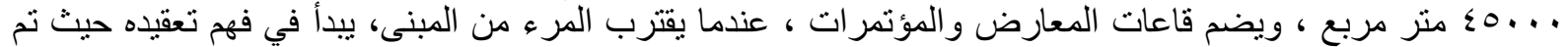

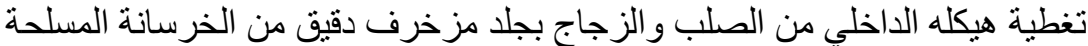

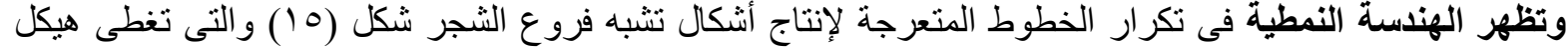

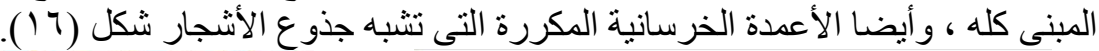

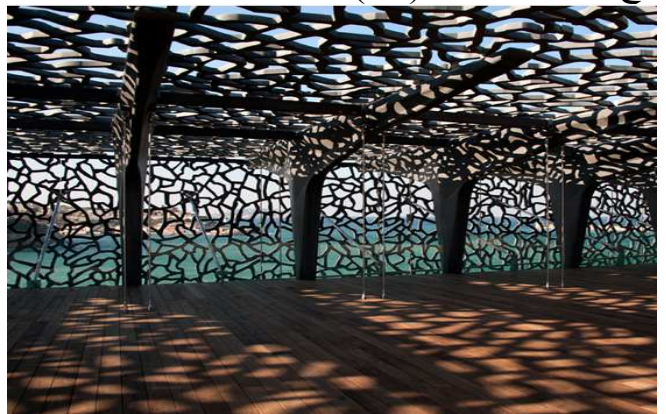

شكل (7 1 ) يوضح الهيكل الداخلى المصنوع من الصلب و الزجاج

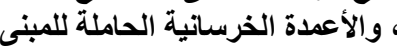

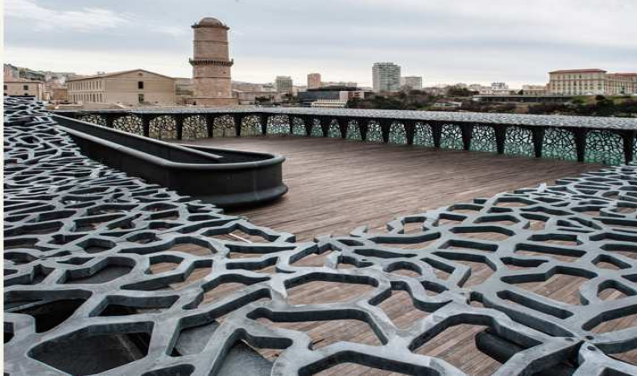

شكل (0 1 ) يوضح شكل سقف المتحف الشبيه بفروع الأشجار فى تكرار خطوطه المتعرجة

ب ق قاعة آتوود للحفلات الموسيقية Evangeline Atwood

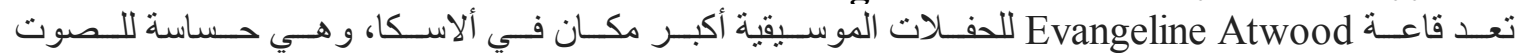

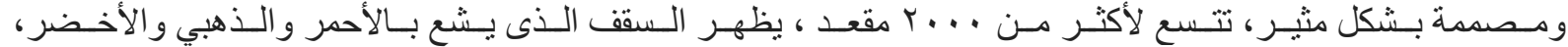
بشكل مذهل ويلتقط تأثير الثفق القطب لتئي. وتظهر الهندسة النمطية فى شكل السقف الذى يشبه الثفق القطبي وخطوطه المتكررة النى تكون أشكال هندسية

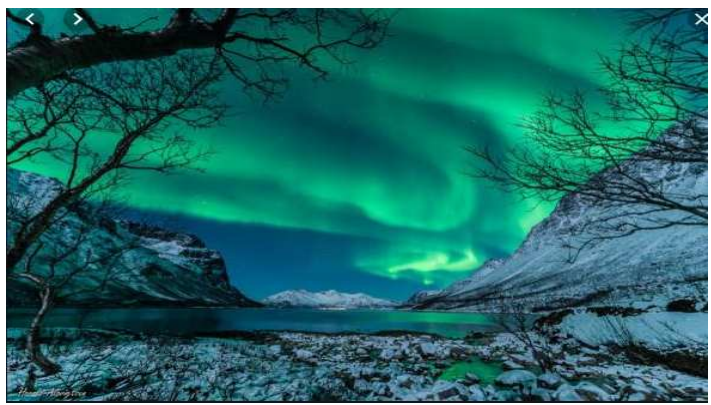

(

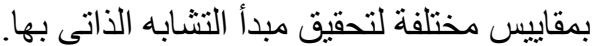

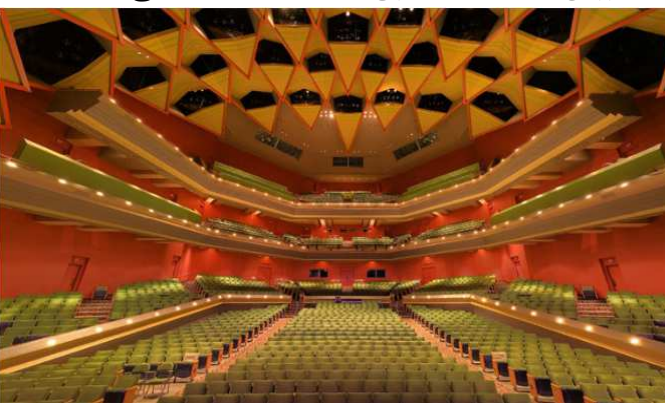

(

شكل(V I ) حيث يوضح ( أ ) الأشكال الهندسية المتكررة فى السقف بمقاييس مختلفة ، ويوضح ( ب ) شكلا من أثكال الثفق القطبى

ج - كلية العلوم والآداب ، الدوحة Doha،Liberal Arts \& Science College

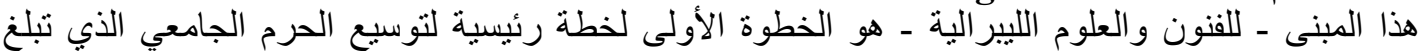

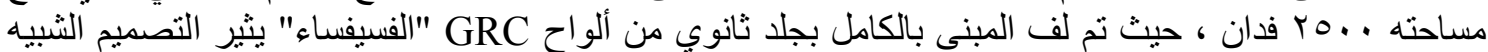

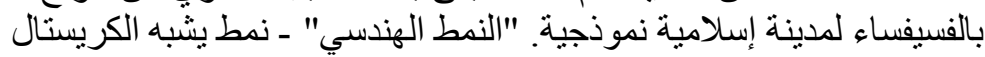

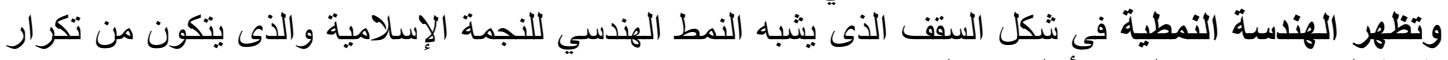

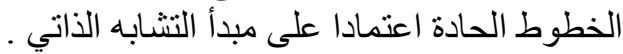




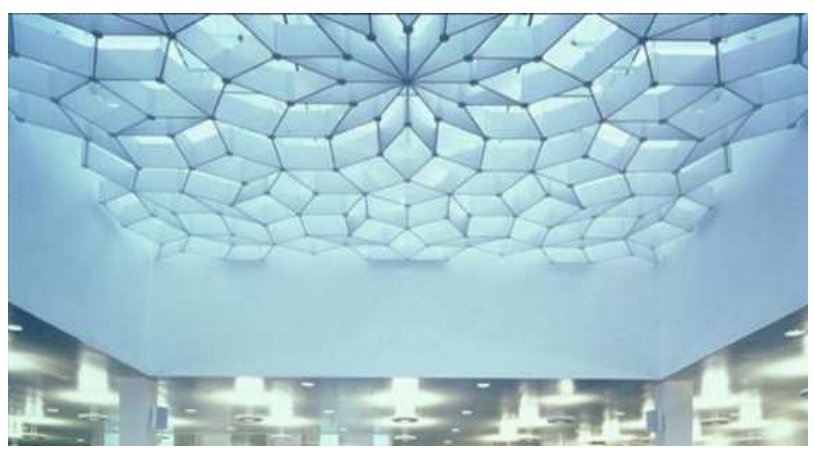

شكل (1 1) يوضح السقف الذى يثبه فى تصميمه النجمة الإسلامية .

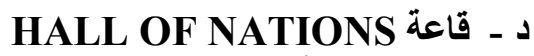

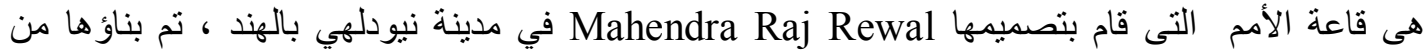

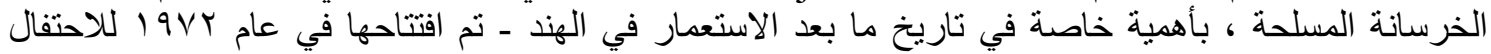
بالذكرى الخامسة و العشرين لاستئة لاستقلال ألبلاد تظهر الهندسة النمطية فى تكرار المنلثات فى مقاييس كبيرة وصغيرة نتشبه فى نمطها شكل مثلث سبربنسكى سواء

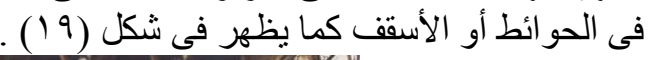

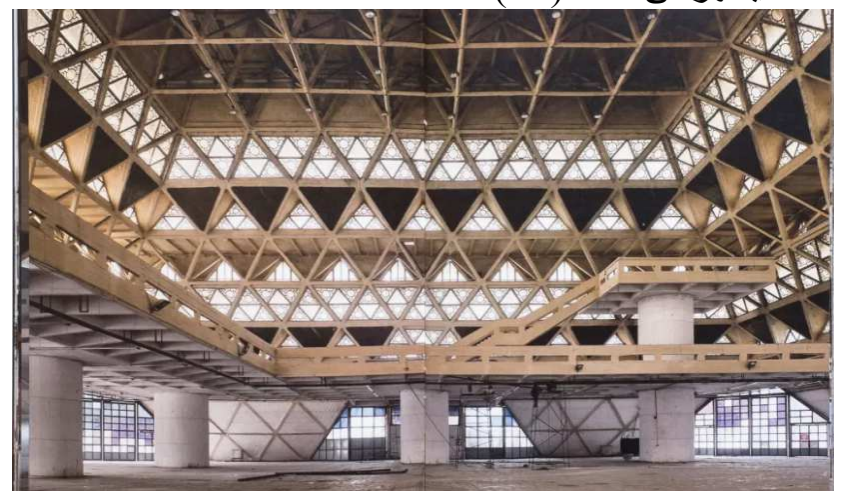

شكل (9 9 ) يوضح القاعة من الداخل والأش هف ؛ 00 ؛ كال المثلثية المتكررة فى الحوائط.

هـ تصميمات اعتمدت على أشكال طبيعيه ذات صفات فراكتاليه:

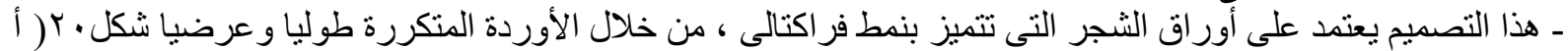

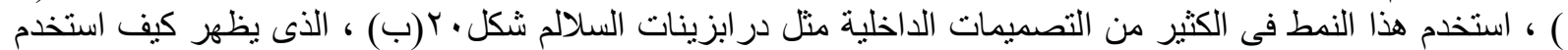
المصمم أوردة أوراق الثجر المتكررة فى صياغة شكل مختلف للاررابزين ويتخذ شكل عضوى ويعتمد على الهندسة

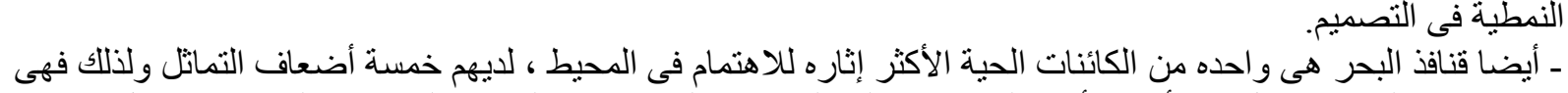

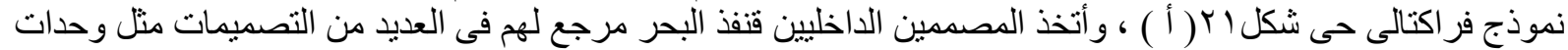

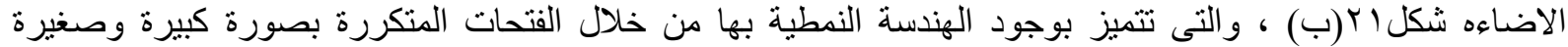
اعتمادا على مبدأ التشابه الذاتى. (التى. 


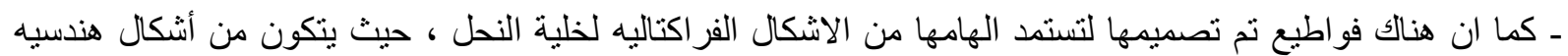
مكرره بكثره بنظام معين لتكوين شكل يشبه خلية النحل، و هو مصنوع من أكسيد الألمونيوم شكل ب ب (أبـب).

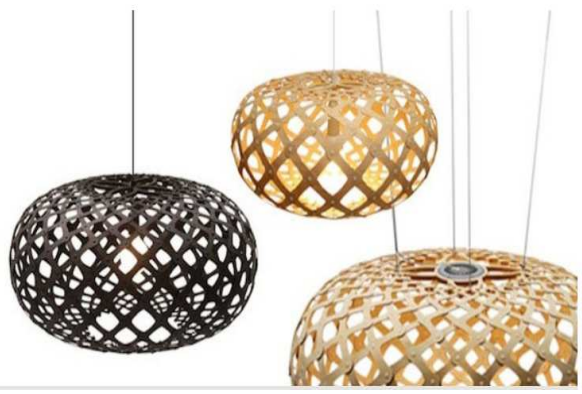

(ب)

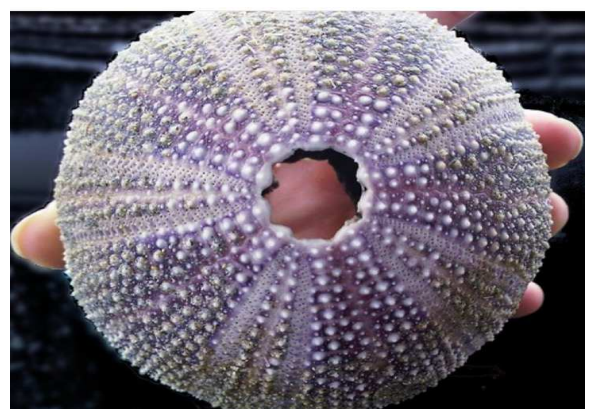

(

شكل • ب ( أ - ب ) يوضح قتفف البحر والخطوط المتكررة على سطده ووحات الاضاءه المعتمدة فى تصميمها عليه .

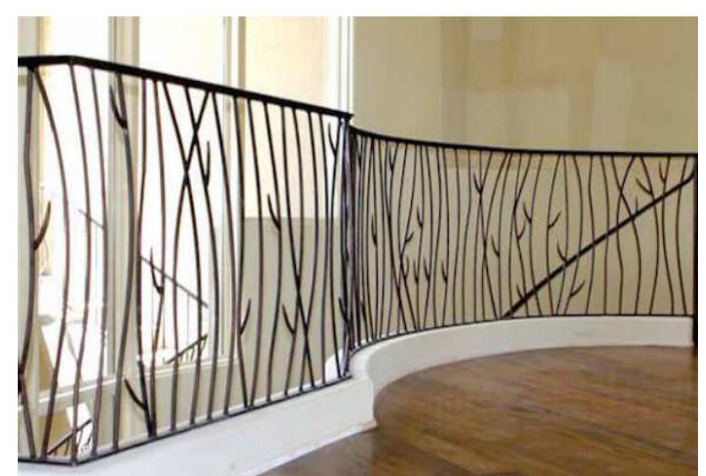

(ب)

شكل ا ץ ( أ ـ ب ) يوضح أوردة أوراق الثجر المتكررة طوليا وعرضي

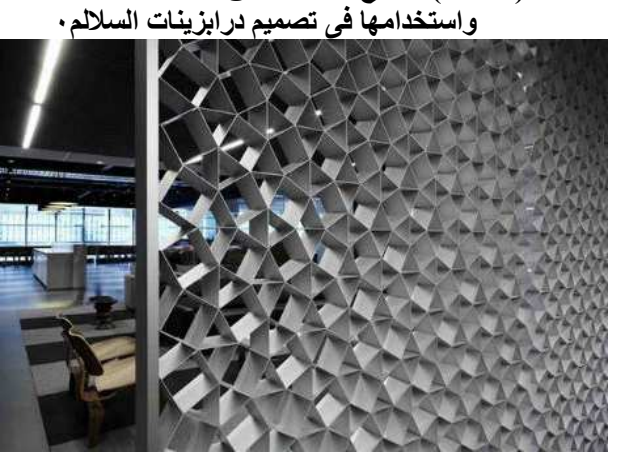

(ب)

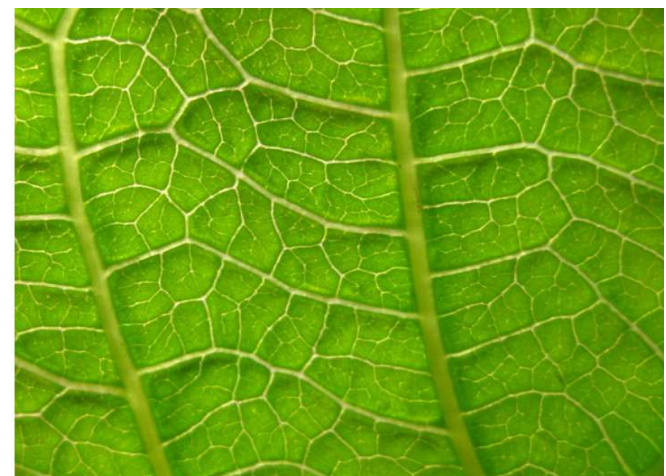

(i)

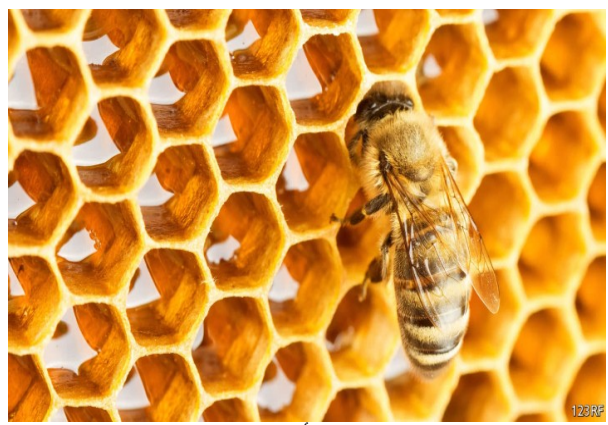

( 1 )

شكل (rr) حيث يوضح ( أ ) شكل خلية النحل الطبيعيه ، ويوضح ( ب ) تصميم القاطوع المشابه لخلية النحل 


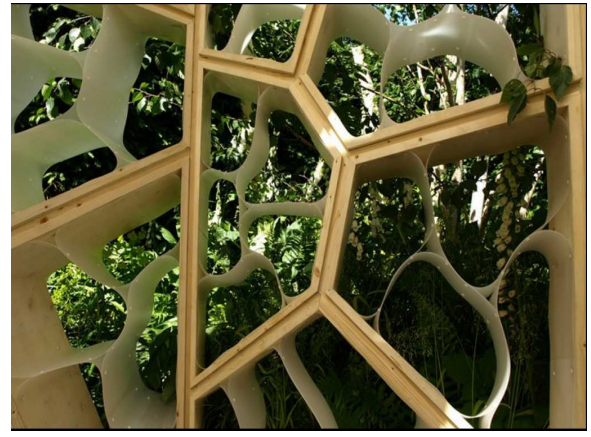

(ب)

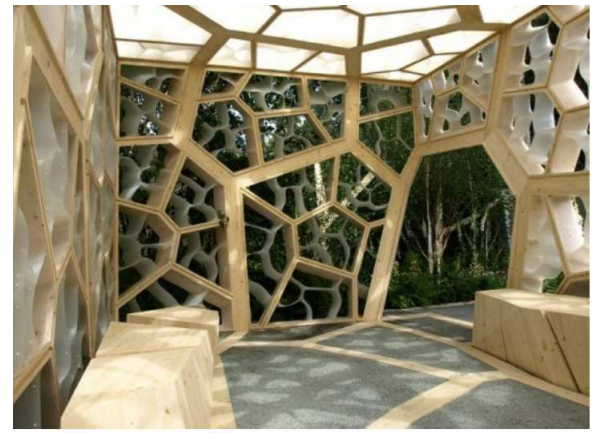

( ( )

شكل(r r حيث يوضح (أ) الحوائط المحاكيه لثكل خلية النحل ، ويوضح (ب) الاشرطه البلاستيكيه.

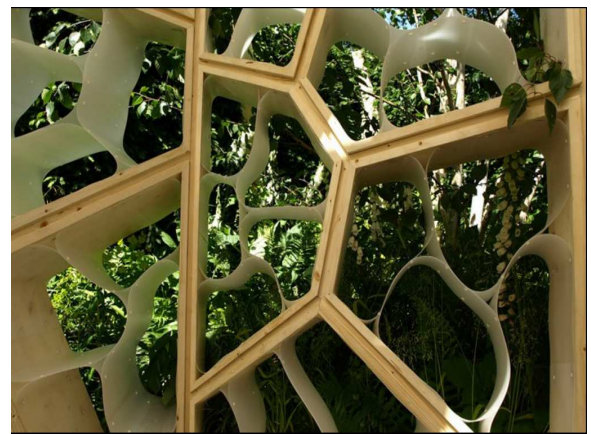

(ب)

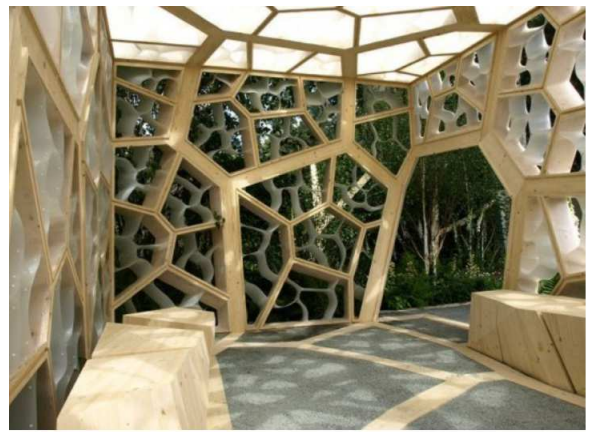

(

شكل(r ץ) حيث يوضح (أ) الحوانط المحاكية لثكل خلية النحل ، ويوضح (ب) الاشرطه البلاستيكية

الأنماط المعقدة المتز ايدة للأور اق ، وفى داخل الجناح تشعر كأنك في رحلة داخل ورقة الثجر، الفروع الرئيسية مصنوعة

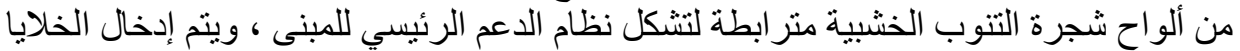

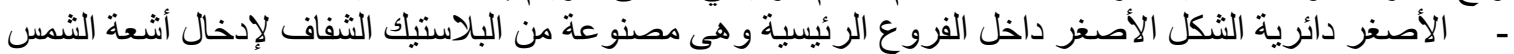
أولا :نتائج البحث:

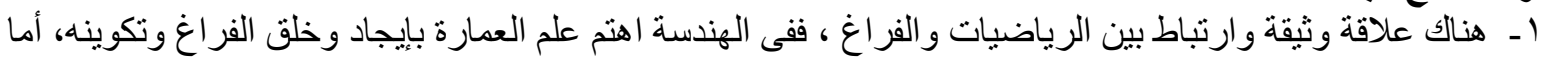

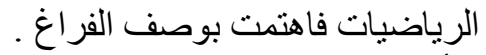

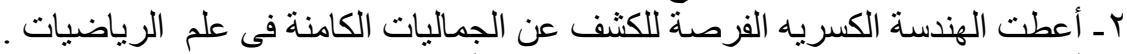

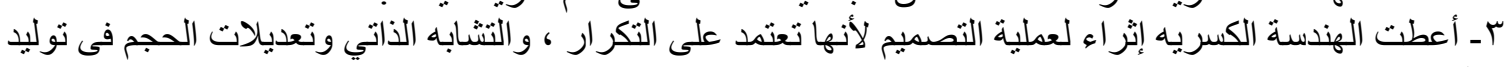

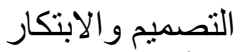

ع ـ أمكن الحصول على التصاميم المعاصرة و المبتكرة من خلال تأثثير التداخل بين التصميم الداخلي و النظريات العلمية

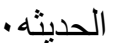

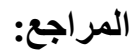
ا ـ شاكر، شيماء عبد العزيز ـ الأساليب التصميمية فى تطبيق طباعة أقشة السيدات ـ مجلة العمارة والفنون ـ العدد الثاني عشر الجزء الثاني

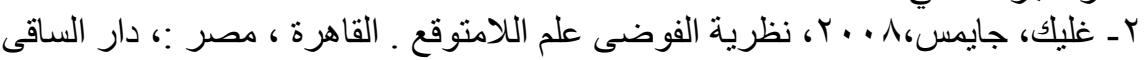

1. Keneth, j . ( june 2013) . Fractal Geometry. Third Edition

2. Andreas, M . The Tower of Hanoi . Myths and Maths. Second edition, Birkhouser

3.Gray, Susan . (1993) . Architects on Architects

4. Batty, Michael, (7 March 2013). Fractals and cities. Simulation Using celluler automate . session 3 : lecture 3

5. Lesmoir, Nigal, (12 march 2018) gordon . Cloud Arent Spheres . World scientific Garcia, Mark .(2014) . Future details of Architecture j6

7- Thames \& Hudson . (2008) . Digital Architecture now. Neil spiller. 